\title{
LA REALIDAD COMO MATERIA NOVELABLE: ALEJO CARPENTIER
}

\author{
¿Por qué pretender buscar en las formas \\ congeladas del realismo socialista la única \\ receta válida? [...] \\ No se pretenda condenar a todas las formas \\ de arte posteriores a la primera mitad del siglo \\ XIX desde el trono pontificio del realismo a ultranza, \\ pues se caería en un error proudhoniano de retorno \\ al pasado, poniéndole camisa de fuerza a la expresión \\ artística del hombre que nace y se construye hoy.
}

ERnesto Che Guevara, 1965

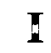

Desde que en 1897 Benito Pérez Galdós defendiera como materia prima legítima de la literatura «la vida misma, de donde el artista saca las ficciones que nos instruyen y embelesan» (Pérez Galdós, 1990: 159), el realismo como instrumento de indagación y análisis de la sociedad no ha dejado de crecer y expandirse. Realismo crítico, como este de Galdós, que implica una ampliación del concepto chato de «realidad», incluyendo en ella «recuerdos, sueños, imaginación, locura, símbolos» para contribuir a la formación de un «realismo total» (Rodríguez Puértolas, 2000, II: 93), al que se une también la asimilación de enseñanzas esenciales como la que representa la narrativa de Cervantes:

La novelística de Galdós hunde sus raíces en el mejor Cervantes, como puede verse en su peculiar sentido del humor y de la ironía, en la concepción perspectivista de la realidad y en tantas otras cosas, algunas de ellas en verdad fundamentales. Así el concepto de la Naturaleza y sus relaciones dialécticas con el ser humano; así el Amor como elemento vital y animador del orden cósmico, muy alejado del idealismo vulgar romántico (Ibid., 93).

Esta tradición crítica no muere con el siglo XIX, sino que se incorpora a las diversas renovaciones experimentadas en los inicios del nuevo siglo, las vanguardias, las nuevas búsquedas expresivas al servicio del mismo objetivo: dar cuenta de qué es y cómọ está organizado eso que llamamos la realidad. El surrealismo será, sin duda, el movimiento que mejor contribuirá a esa ampliación de la noción de realidad: «el surrealismo descansa sobre la creencia en la realidad superior de ciertas formas de asociaciones despreciadas hasta él y a la todopoderosa acción del sueño y en el juego desinteresado del pensamiento» (Carpentier, 1991: 23). El subconsciente adquiría así rango de igualdad con la 
consciencia, incluso con un valor más destacado que esta última, ya que permitiría descubrir aquello que conscientemente era escondido durante los estados de vigilia. Esta actitud sí representaba una verdadera ruptura con lo anterior:

La importancia del surrealismo es que hasta el surgimiento de esa escuela todos los artistas, todos los escritores, todos los poetas habían tratado de suscitar la emoción mediante un objeto artístico, mediante una voluntad estética, controlada por la lógica (Carpentier, 1991: 23).

Pero esta técnica también acabó convirtiéndose en eso, en técnica, abandonando la no manipulación del inconsciente liberado de todo control social:

Y empezaron a fabricar, fabricar - insisto en la palabra - encuentros fortuitos de objetos, buscan los dos objetos más disímiles y los metían en un cuadro [...]. Situación insólita. Pero eso es fabricado.

¿Sueños? Breton reconoce que llegó un momento en que los hombres empezaron, los del grupo, a fabricar sueños, a inventar sueños, a dar como visiones subconscientes unas visiones perfectamente fabricadas, tan enmendadas y tan cuidadosamente escritas, como puede ser un soneto parnasiano (Carpentier, 1991: 212-213).

Sin embargo, las enseñanzas del surrealismo no se perderían y lo que en la tradición cultural europea se había transformado en un juego artístico más sirvió para sentar las bases de un acercamiento nuevo a la realidad americana.

\section{II}

Si los escritores hispanoamericanos posteriores a la independencia habían intentado bien asimilarse a las tradiciones europeas, bien desarrollar un nacionalismo literario «empleando un lenguaje florido y lleno de americanismos» (Carpentier, 1999: 40), el descubrimiento de las propias peculiaridades a finales del XIX permite a estos escritores ir dando cuenta de una realidad que en nada se asemeja a la europea:

El hombre aquí está avasallado por la naturaleza [...] Apenas se sale del perímetro de las ciudades, una existencia extrañamente primitiva nos acecha. Ayer fue que las bombillas eléctricas reemplazaron sin transición a la lámpara de aceite. Si usted desea viajar a Bogotá, escogerá entre muchas jornadas en barco en un río pululante de cocodrilos y algunas horas en avión. Llanuras que parecen llevar a la Luna, Andes, selvas como sólo conoció Europa en sus tiempos cuaternarios... [...]. Esto genera un tema perenne situado en la base de toda novela moderna de América Latina: el ser humano, en guerra encarnizada contra un medio que lo asedia, lo acosa, lo golpea y proponiéndose encontrarse a sí mismo, definirse - patética búsqueda de sí mismo, contextuada por un combate librado contra otros hombres, contra todo o que se mueve, contra potencias mudas: montes, árboles, soledad (Carpentier, 1999: 39-40).

Esta observación de la realidad en la que existe el hombre americano ha dado lugar a una de las teorías más fructíferas desarrolladas por Alejo Carpentier, sin duda, uno de los fundadores de la llamada nueva novela hispanoamericana y responsable en buena medida 
de lla inclusión de esta literatura en la tradición cultural occidental. Cubano exiliado en París en 1928 huyendo de la dictadura de Machado en su país, Carpentier se incorpora al movimiento surrealista francés fascinado por esa nueva forma de acercamiento a la realidad. Pero con una lucidez absoluta, el autor cubano renuncia a aumentar el número de creaciones surrealistas y se concentra durante su estancia en Europa en la lectura de cuanto libro encuentra relacionado con la historia de su continente de origen. Este acercamiento libresco a la realidad y la historia americana tendrá su contrapartida práctica en 1943 cuando de vuelta en América realice un viaje a Haití y se enfrenté a una realidad que sin la experiencia europea es probable que no hubiese sido mirada como lo fue. El conocimiento del proceso de independencia de Haití, que luego pasaría a convertirse en novela en El reino de este mundo, de la vigencia arquitectónica del delirio de Henri Christophe, primer monarca americano, y la convivencia cotidiana de elementos que los surrealistas franceses sólo encontraban unidos en sus sueños o en sus pinturas, abrió los ojos del escritor a lo real maravilloso: «Aquí lo insólito es cotidiano, siempre fue cotidiano» (Carpentier, 1984: 122). Siempre, porque desde el momento en que se produce la llegada de los europeos al nuevo continente, todo lo que allí encuentran supera con mucho la realidad conocida, de tal manera que el referente utilizado para comparar esa nueva realidad será literario, libresco, mitológico, porque nada de lo conocido puede servir como parámetro, vara de medir o punto de referencia que permita un acercamiento y una explicación:

En el Atlas universal de Garnier, de 1889 - no hace cien años-, se nos dice que el área urbana de Madrid era entonces de veinte kilómetros, y la de París, capital de las capitales, de ochenta kilómetros. Pues bien, cuando Bernal Díaz del Castillo se asomó por primera vez al panorama de la ciudad de Tenochtitlán, la capital de México, el imperio de Moctezuma, tenía un área urbana de cien kilómetros cuadrados (Carpentier, 1984: 122).

Esta desmesura afecta a todos los aspectos con los que se enfrentaron los conquistadores, pero, después de quinientos años, la desmesura no ha decrecido ni un ápice: países que en cien años de independencia han sufrido más de ciento cincuenta golpes militares; huracanes, volcanes y terremotos que siguen destruyendo ciudades y pueblos como si nunca antes hubieran existido; una economía regida por intereses extranjeros que transforma a un país en proveedor mundial de un solo producto enriqueciéndolo para dejarlo caer en el vacío de la ruina estatal si la materia prima tan codiciada deja de serlo al cabo de pocos años. La conciencia de estas particularidades lleva a Carpentier a desarrollar la «Teoría de los contextos» como instrumento imprescindible de acercamiento a la realidad americana que será trasladada a la novela.

\section{III}

La definición de novela que nos ofrece el diccionario de la RAE (vigésimo segunda edición, 2001) no tiene desperdicio: «Obra literaria en prosa en la que se narra una acción fingida en todo o en parte, y cuyo fin es causar placer estético a los lectores con la descripción o pintura de sucesos o lances interesantes, de caracteres, de pasiones y de costumbres». Tan vaga definición encierra, sin embargo, toda una ideología de qué cosa 
sea la literatura, ya que aparece descrita como un producto de consumo ajeno al mundo circundante que permite su aparición con las características propias de cada obra.

Alejo Carpentier, al desarrollar su teoría de la novela, da de lleno en el problema que dicha definición ofrece: la novela debe «violar constantemente el principio ingenuo de ser relato destinado a causar "placer estético a los lectores", para hacerse un instrumento de indagación, un modo de conocimiento de hombres y de épocas» (Carpentier, 1984: 8). De esta forma, el texto narrativo elude ser enmarcado como objeto de ocio para adquirir una trascendencia esencial en el conocimiento ontológico del hombre y de su devenir histórico. Todo lo que se aleje de esta intención no es novela, sino mera narración: «La novela debe llegar más allá de la narración, del relato, vale decir: de la novela misma, en todo tiempo, en toda época, abarcando aquello que Jean Paul Sartre llama "los contextos"» (Carpentier, 1984: 9).

La teoría de los contextos de Alejo Carpentier parte, pues, de la idea de que la función de la novela no se limita a narrar una historia, sino que debe dar cuenta de la situación histórica, social y geográfica en que se sitúa el relato, o en palabras del autor: «¿Dónde vive, palpita, resuella, sangra, gime, clama, la época tremebunda, hecha de contextos, que es la nuestra?» (Carpentier, 1984: 15). Porque se trata de eso, de dar cuenta de nuestra época, de la realidad en la que existimos como seres humanos, de las condiciones que nos trajeron a esta situación, de las esperanzas que sobreviven: «Carpentier busca en el pasado las respuestas para el porvenir» (Millares, 2004: 110).

En el caso concreto de Latinoamérica, los contextos que enumera el escritor cubano son los siguientes: raciales; económicos; ctónicos; políticos; burgueses; de distancia y proporción; de desajuste cronológico; culturales; culinarios; de iluminación; ideológicos; del estilo; de la dimensión épica. Estas serían las claves para levantar el armazón de una novela que pretenda indagar en la identidad americana, claves que le dan al escritor todo el fondo y la técnica que debe contener la narración elegida. De esta forma, la novela se transforma en un recipiente donde late la vida y la historia de un continente. Es obvio que cualquier cultura cuenta con esos contextos, pero Carpentier lo que hace es señalar qué hay de específico en los americanos que no es posible encontrar en otros lugares: la mezcla de razas y los distintos niveles culturales que hacen convivir en épocas distintas a los ciudadanos de un mismo país; los dictados foráneos en la marcha económica de países «independientes» y sus consecuencias sobre la población; la supervivencia de creencias remotas frente a nuevas imposiciones; la inestabilidad política, la utilización de los ejércitos como fuerzas de represión internas; la injerencia extranjera; la inestabilidad del pequeño burgués en su posición social; la naturaleza indomesticable que impone sus ritmos y violencias; el retraso con que llegan movimientos culturales y políticos ya periclitados en otros lugares del mundo; un enfoque cultural que agrupa muy diversas tradiciones y por tanto permite una visión del mundo más amplia que en otros lugares, siempre que conocer no equivalga a someterse; una tradición culinaria que es también cultural, histórica y mestiza; la luz como elemento de identificación y definición de cada ciudad americana; unos contextos ideológicos «poderosos y presentes» (Carpentier, 1984: 24) que no deben, sin embargo, transformar la literatura en tribuna, porque «los libros que conmueven al mundo, por emplear un slogan de buena ley, no son novelas: se titulan El contrato social o El capital» (Carpentier, 1984: 25).

Como es obvio, todos ellos están interrelacionados y su aparición en las novelas del escritor cubano no se organiza como un catálogo de características más o menos localis- 
tas, sino erigiéndose en la razón que explica por qué ocurre lo que ocurre en el texto. Pero si hablamos de novela, Carpentier no olvida el estilo que para dar cuenta de una realidad tan compleja y nueva todavía es necesario, el barroco:

la prosa que le da vida y consistencia, peso y medida, es una prosa barroca, forzosamente barroca, como toda prosa que ciñe el detalle, lo menudea, lo colorea, lo destaca, para darle relieve y definirlo (Carpentier, 1984: 26).

Adentrarse en cualquiera de sus novelas significa en primer lugar enfrentarse a una explosión verbal que no puede por menos que dejar desconcertado al lector acomodado y convertirse en un acicate para el lector interesado. Una riqueza de vocabulario que se abre ante nosotros para darnos la bienvenida a un universo que es real, sin embargo, hasta en eso, puesto que todo ese léxico es una representación de la realidad latinoamericana. Una realidad que Carpentier no limita a un solo país, ya que sus obras son un catálogo de vocabulario panhispánico, en un deseo de poner ante el lector la riqueza de sinónimos con que puede ser nombrada la realidad en aquel continente. El estilo barroco no es gratuito o caprichoso para el escritor latinoamericano, es un ejercicio de coherencia:

Nuestro mundo es barroco por la arquitectura - eso no hay ni que demostrarlo-, por el enrevesamiento y la complejidad de su naturaleza y su vegetación, por la policromía de cuanto nos circunda, por la pulsión telúrica de los fenómenos a que estamos todavía sometidos (Carpentier, 1984: 123).

Mostrar una realidad así exige un estilo en consonancia que no desvirtúe la impresión que dicha realidad provoca en el observador, es decir, en el lector, y que puede definirse recurriendo a su variedad arquitectónica como hace el propio Carpentier en multitud de ocasiones, de manera que el barroco

Se caracteriza por el horror al vacío, a la superficie desnuda, a la armonía lineal-geométrica, estilo donde en torno al eje central - no siempre manifiesto ni aparente - [...] se multiplican lo que podríamos llamar los «núcleos proliferantes», es decir, elementos decorativos que llenan totalmente el espacio ocupado por la construcción, las paredes, todo el espacio disponible arquitectónicamente, con motivos que están dotados de una expansión propia y lanzan, proyectan las formas con una fuerza expansiva hacia fuera. Es decir, es un arte en movimiento, un arte de pulsión, un arte que [...] va rompiendo, en cierto modo, sus propios márgenes (Carpentier, 1991: 112).

Según todo esto, es la fidelidad a la realidad que se quiere retratar y analizar en los textos la que impone un estilo concreto que no falsee su naturaleza, pero sin olvidar que «no tiene nada que ver, ideológicamente, con el español y católico del siglo XVII» (Rodríguez Puértolas, 1988: 89), o en palabras de Eduardo Galeano:

Alejo Carpentier emplea la expresión «barroco» en un sentido que nada tiene que ver con el churrigueresco discurso, ampuloso y vacío, de otros escritores. Para Carpentier, el barroco resulta de la mezcla de estilos y de culturas que genera en nuestras tierras, «lo 
real maravilloso», y tiene un sentido original y vital, por completo ajeno a la mirada colonial que desde fuera nos petrifica en el paisaje exótico y en las imágenes de exportación (Galeano, 1996: 27).

El alejamiento de posturas tradicionalistas conectadas con el barroco español del Siglo de Oro se pone de manifiesto en la profunda asimilación que hace Carpentier de la obra de Cervantes (un interesante punto de contacto con Galdós, de nuevo). Como ha señalado Selena Millares (2004: 111-116), la presencia del escritor español en la obra carpenteriana se acentúa especialmente a partir de la década de los setenta, es decir en su producción final, en lo que podría considerarse un «diálogo, más allá del tiempo, con el maestro español» (Ibid., 114). Pero no se trata sólo de la utilización de citas textuales, sino de una conexión más profunda. Por poner un ejemplo, la presencia de Cervantes en El arpa y la sombra es un substrato constante que relaciona las palabras de Colón con $E l$ retablo de las maravillas para poner de manifiesto no sólo la vacuidad del discurso del futuro descubridor ante las cortes europeas, sino la disponibilidad a ser engañados por parte de quienes le escuchan ${ }^{1}$.

\section{IV}

El estilo de la nueva literatura que Carpentier proponía para el continente americano quedaba fijado entonces por el entorno en el que surgía, pero lo mismo ocurría con los temas elegidos. Todas las novelas del autor cubano están centradas en dar testimonio de algún aspecto de la historia americana, historia que abarca desde la conquista hasta el siglo $\mathrm{XX}^{2}$. Tanto es así, que es considerado el creador de un subgénero literario denominado «nueva novela histórica» (Menton, 1993: 38-42). El armazón de sus creaciones de ficción es siempre un compendio de hechos reales, lo que se ha denominado el «documento», que «no es otra cosa que aquello que adopta el artista como la materia prima, o la fuente, histórica o real, que va a transformar en su obra» (Vázquez, 2003: 215).

Este interés por la historia forma parte del sistema literario que elabora Carpentier en cada uno de sus textos teóricos o ensayísticos y que pone en práctica en cada una de las novelas que publica. El descubrimiento de un «maravilloso real» frente a lo maravilloso suscitado artísticamente pasaba necesariamente por el acercamiento a una historia que se ve como componente esencial de la realidad («¿Pero qué es la historia de América toda sino una crónica de lo real-maravilloso?»; Carpentier, 1964: XV), y de ahí a ese realismo crítico y ampliado que mencionábamos al principio, porque

1 Esta utilización del creador de la novela moderna, en palabras de Américo Castro, es una tradición hispanoamericana que debemos retrotraer al Modernismo. Efectivamente, tanto Martí como Rubén Darío alaban al autor del Quijote, personaje este que, además, sienten relacionado con sus luchas de independencia, véase, por ejemplo, un cuento de Darío titulado «D. Q.». Por su parte, Carpentier, como señala Millares (2004: 114), hizo en 1940 una adaptación radiofónica de Don Quijote, novela que eligió para iniciar su labor como director de las Ediciones del Estado en Cuba en 1964 con una tirada de cuatrocientos mil ejemplares.

2 Carpentier se ha ocupado en escasas ocasiones de la América precolombina, pero no es un tema completamente ajeno a su producción literaria. Así, el cuento «Los advertidos», que desentraña el mito del diluvio universal según las creencias indígenas. Por otra parte, su novela Los pasos perdidos incluye el pasado del continente anterior a la conquista gracias precisamente a su teoría de los contextos. 
no será, pues, en las visiones de la literatura sino en las visiones de la historia; no en la imaginación onírica sino en las ruinas verdaderas; no en la geografía de los libros sino en la topografía real donde habrá de encontrar Carpentier lo maravilloso (Rodríguez Monegal, 1972: 118).

Esto da lugar a un sistema de trabajo basado en «el afán de exactitud y de rigurosidad (de verosimilitud) [que] hace que Alejo Carpentier se documente hasta el detalle» (Rodríguez Puértolas, 1998: 45). Documentación imprescindible en un autor empeñado en mostrar, no un mundo imaginario, sino el maravilloso mundo real americano, es decir, un escritor para el que la realidad es el único tema digno de interés en sus composiciones narrativas. Esta actitud tiene mucho que ver con la función que Carpentier otorga al novelista, al que considera obligado a dar cuenta de la realidad en que vive inmerso: «nunca he podido establecer distingos muy válidos entre la condición del cronista y la del novelista. Al comienzo de la novela, tal como hoy la entendemos, se encuentra la crónica» (Carpentier, 1984: 160). Y añade:

Por lo tanto, no veo más camino para el novelista nuestro en este umbral del siglo XXI que aceptar la muy honrosa condición de cronista mayor, Cronista de Indias, de nuestro mundo sometido a trascendentales mutaciones (Ibid., 161).

No cabe duda que en lo que se refiere a sí mismo, Alejo Carpentier se mantuvo fiel a la misión de convertir la novela en instrumento de indagación de la realidad, que no es otra cosa que instrumento al servicio de un ser humano al que devolver su papel de protagonista de la historia ${ }^{3}$; como afirma Carmen Vásquez, «Carpentier cumplió con la triple función que se impuso a sí mismo como escritor americano, que es la de ser a la vez novelista, investigador e historiador y que lo llevó a asumir también el papel de rescatador de patrimonios, es decir, de la memoria americana» (Vásquez, 2003: 222).

\section{$\mathbf{V}$}

Aspecto fundamental es la concepción que Carpentier desarrolla en sus textos narrativos de la evolución de los procesos históricos y que ha sido discutida y enfocada desde presupuestos en buena medida contradictorios. Mientras Roberto González Echevarría (1978: 142) considera que estamos ante una repetición cíclica «que desemboca en lo estático y permanente, como los idénticos rayos de una rueda en movimiento proyectan una imagen fija», otros críticos han profundizado en «la presencia actuante de las leyes dialécticas» (Bueno, 1977: 211), que determinarían, en palabras de este mismo crítico, «la evolución en espiral de la Historia» (Ibid., 212). En su fidelidad al hecho histórico narrado, Carpentier no puede inventar finales felices donde no los hay, así la sucesión de esclavizaciones a que son sometidos los negros haitianos por sus propios compañeros en El reino de este mundo, así la corrupción de los ideales de la Revolución francesa en $E l$ siglo de las luces, así el fin de «las vacaciones de Sísifo» en Los pasos perdidos. Pero como muy bien ha señalado Fernando Alegría (1970: 69-70), la repetición cíclica, que

3 Relacionado con este aspecto es esencial el concepto de novela épica que tiene el autor y su defensa de un protagonista colectivo o anónimo. Véase Carpentier (1984: 28-29). 
supone un planteamiento histórico pesimista, una aceptación del mito del eterno retomno ${ }^{4}$, es vencida en la obra de Alejo Carpentier por una constante lucha del Hombre por la libertad. Estamos ante héroes que se esfuerzan por crear un mundo mejor del que ellos no disfrutarán:

Y comprendía, ahora, que el hombre nunca sabe para quién padece y espera. Padece y espera y trabaja para gentes que nunca conocerá, y que a su vez padecerán y esperarán y trabajarán para otros que tampoco serán felices, pues el hombre ansía siempre una felicidad situada más allá de la porción que le es otorgada. Pero la grandeza del hombre está precisamente en querer mejorar lo que es (Carpentier, 1964: 135).

Por tanto, el círculo se puede romper y es la lucha por romperlo lo que da sentido a la existencia humana. De ahí la importancia que tiene la Revolución como tema de esta novelística, la Revolución como componente esencial de la realidad que se quiere mostrar y motor de las acciones humanas, como evidencia su última gran novela, La consagración de la primavera.

La producción narrativa de Alejo Carpentier está presidida, sin duda, por el grito de Sofía en El siglo de las luces:

- ¿Quédate si quieres! ¡Yo voy!

$-¿ Y$ vas a pelear por quién?

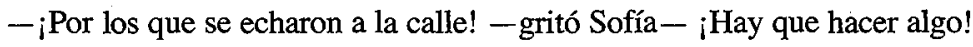

-¿Qué?

- ¡Algo!

Novelística de la historia, de la realidad, del lenguaje barroco, del descubrimiento de lo real maravilloso, todo con el único objetivo válido: modificar la realidad. Porque como ya dijera alguien en el siglo XIX, «los filósofos [y podríamos añadir los escritores] no han hecho más que interpretar de diversos modos el mundo, pero de lo que se trata es de transformarlo» (Marx, 1974: 229).

4 Julio Rodríguez Puértolas reproduce la siguiente opinión de Carpentier sobre este tema: «El primero en sostener que la historia era un eterno recomenzar, además de que no había visto el comienzo, tenía una rara noción de lo que se llama eternidad» (Rodríguez Puértolas, 1988: 91). 


\section{BIBLIOGRAFÍA}

Alegría, Fernando (1970): «Alejo Carpentier: Realismo mágico». En: Homenaje a Alejo Carpentier. Helmy F. Giacoman (ed.), Nueva York: Las Americas Publishing, 33-70.

Bueno, Salvador (1977): «La serpiente no se muerde la cola». En: Recopilación de textos sobre Alejo Carpentier, La Habana: Casa de Las Américas, 201-218.

Carpentier, Alejo (1964): El reino de este mundo. La Habana: Ediciones Unión.

(1984): Ensayos. La Habana: Editorial Letras Cubanas.

(1986): El siglo de las luces. Santiago de Chile: Biblioteca Ayacucho.

(1991): Conferencias, vol. 14 de las Obras completas. México: Siglo XXI.

(1999): «Puntos cardinales de la novela en América Latina». En: La Gaceta de Cuba, 6, noviembre-diciembre, 39-41.

Galeano, Eduardo (1996): El tigre azul y otros artículos. La Habana: Ciencias Sociales.

González Echevarría, Roberto (1978): «Alejo Carpentier». En: Narrativa y crítica de nuestra América. Joaquín Roy (coord.). Madrid: Castalia, 127-160.

Marx, Carlos (1974): Tesis sobre Feuerbach. México: Ediciones de Cultura Popular.

Menton, Seymour (1993): La nueva novela histórica de la América Latina, 1979-1991. México: FCE.

Millares, Selena (2004): Alejo Carpentier. Madrid: Síntesis.

Pérez Galdós, Benito (1990): Ensayos de crítica literaria. Edición de Laureano Bonet. Barcelona: NeXos.

Rodríguez Monegal, Emir (1972): «Lo real y lo maravilloso en El reino de este mundo». En: Asedios a Carpentier. Edición de Klaus Müller-Berg. Santiago de Chile: Editorial Universitaria, 101-132.

Rodríguez Puértolas, Julio; Blanco Aguinaga, Carlos y Zavala, Iris M. (2000): Historia social de la literatura, 2 vol. Madrid: Akal.

Rodríguez Puértolas, Julio (1988): «Significación de Alejo Carpentier». En: Alejo Carpentier. Barcelona: Anthropos, 81-102.

(1998): «Introducción biográfica y crítica». En: Alejo Carpentier, La consagración de la primavera. Madrid: Castalia, 7-89.

Subercaseaux, Bernardo (1977): «El reino de la desalienación». En: Recopilación de textos sobre Alejo Carpentier. La Habana: Casa de las Américas, 323-332.

Vásquez, Carmen (2003): «Los primeros pasos». En: Alejo Carpentier et "Los pasos perdidos". París: INDIGO, 213-223.

Velayos Zurdo, L. Óscar (1990): Historia y utopía en Alejo Carpentier. Salamanca: Ediciones Universidad de Salamanca. 